\title{
Innovación docente en el ámbito de las ciencias jurídicas: una aproximación desde el Derecho Internacional Público
}

\section{Teaching innovation in the field of legal sciences: an approach from Public International Law}

LAURA García MARTíN

ORCID: 0000-0003-0163-9108

Universidad de Sevilla

Departamento de Derecho Internacional

Público y Relaciones Internacionales

lgarcia17@us.es

Fecha de recepción: 18/06/2019

Fecha de aceptación: 25/06/2019

DOI: http://dx.doi.org/10.12795/9788447221912.057

Pp.: 1308-1327 


\section{Resumen}

El presente artículo aborda el desarrollo de un ciclo de mejora docente desarrollado en la asignatura de Derecho Internacional Público del Grado en Derecho durante el segundo cuatrimestre del curso 2018/2019. A través del mismo, se plantea una aproximación docente eminentemente de carácter práctico, en la que el profesor actúa como facilitador del proceso de aprendizaje pero son los alumnos quienes desempeñan un papel fundamental para alcanzar los objetivos de enseñanza fijados.

Palabras clave: Ciclos de Mejora en el Aula, Derecho Internacional Público, Grado en Derecho, docencia universitaria, experimentación docente universitaria.

\section{Abstract}

This paper addresses the development of a teaching improvement cycle developed in the subject of Public International Law of the Degree in Law, during the second semester of the academic course 2018/2019. It presents a practical teaching approach in which the Professor acts as a facilitator for the learning process, although the students are the protagonists, playing a fundamental role in achieving the teaching objectives previously setted.

Key words: Improvement Cycles in Classroom, Public International Law, Law Degree, university teaching, university teaching experimentation.

Jornadas de Formación e Innovación Docente del Profesorado | № 2 (2019) Esta obra se distribuye con la licencia Creative Commons Reconocimiento-NoComercial-SinObraDerivada 4.0 Internacional (CC BY-NC-ND 4.0.) 


\section{Breve descripción del contexto}

El presente diseño aborda un ciclo de mejora docente para un total de 12 horas de clase de la asignatura Derecho Internacional Público del grado en Derecho, tratándose de una asignatura anual y obligatoria que se imparte en el segundo curso de dicho Grado. El grupo en cuestión en el que se va a desarrollar este ciclo de mejora consta de 70 alumnos matriculados, de los cuales 40 asisten a clase con regularidad. Las clases se imparten lunes, martes y miércoles de 12:30 a 13:30.

\section{Diseño previo del Ciclo de Mejora Docente}

\section{Mapa de Contenidos}

Este ciclo de mejora se ha diseñado para la lección 17 (El arreglo de controversias) y la lección 18 (Control del uso de la fuerza en Derecho Internacional Público). Los contenidos más relevantes de este tema se han organizado en un mapa de contenido que se muestra en las siguientes figuras: 


\section{LaURa García Martín}

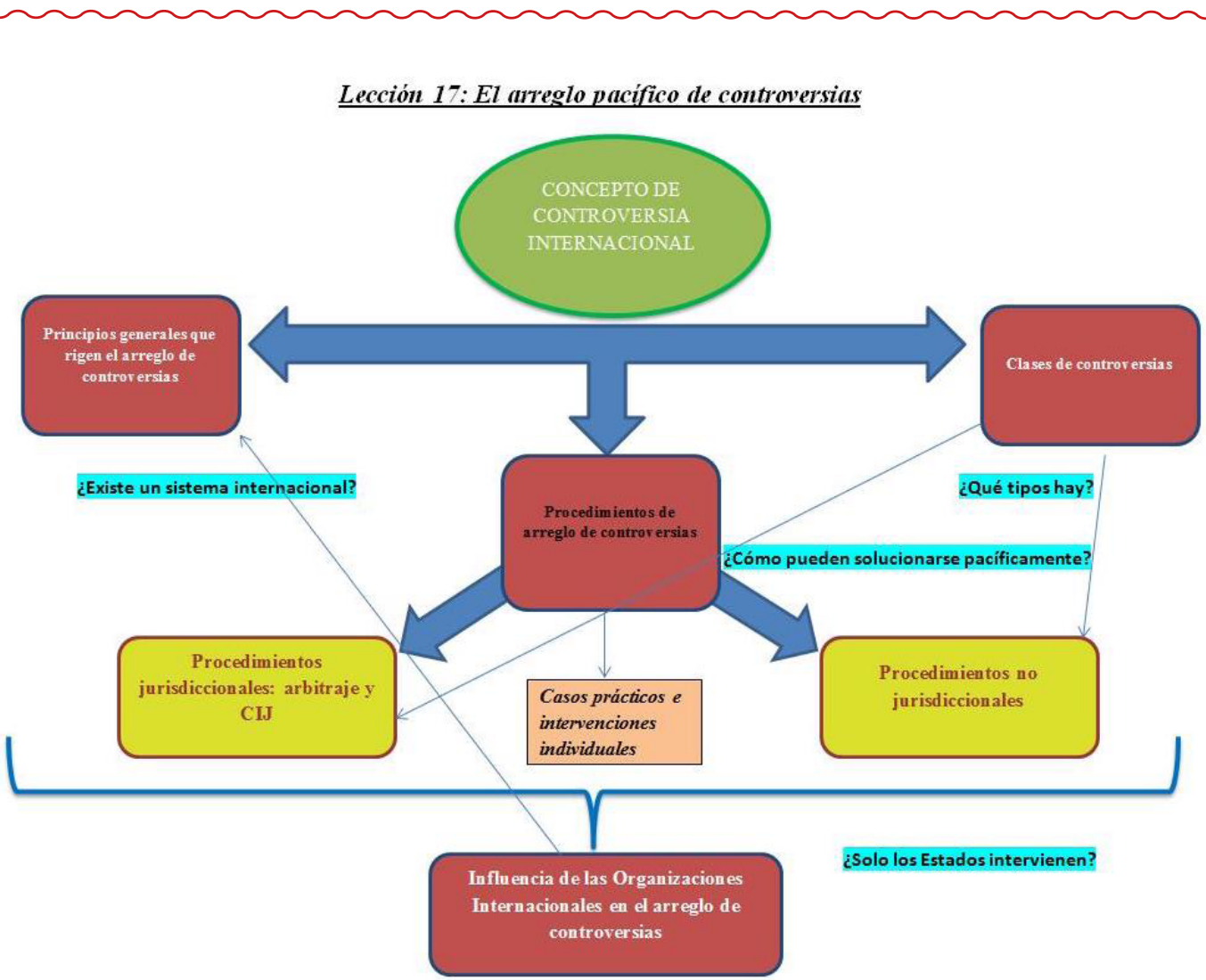

Figura 1. Mapa de contenidos de la lección 17

Jornadas de Formación e Innovación Docente del Profesorado | № 2 (2019) Esta obra se distribuye con la licencia Creative Commons

Reconocimiento-NoComercial-SinObraDerivada

Internacional (CC BY-NC-ND 4.0.) 


\section{LAURA GARCía MARTíN}

\section{Lección 18: El control del uso de la fuerza en Derecho Internacional}

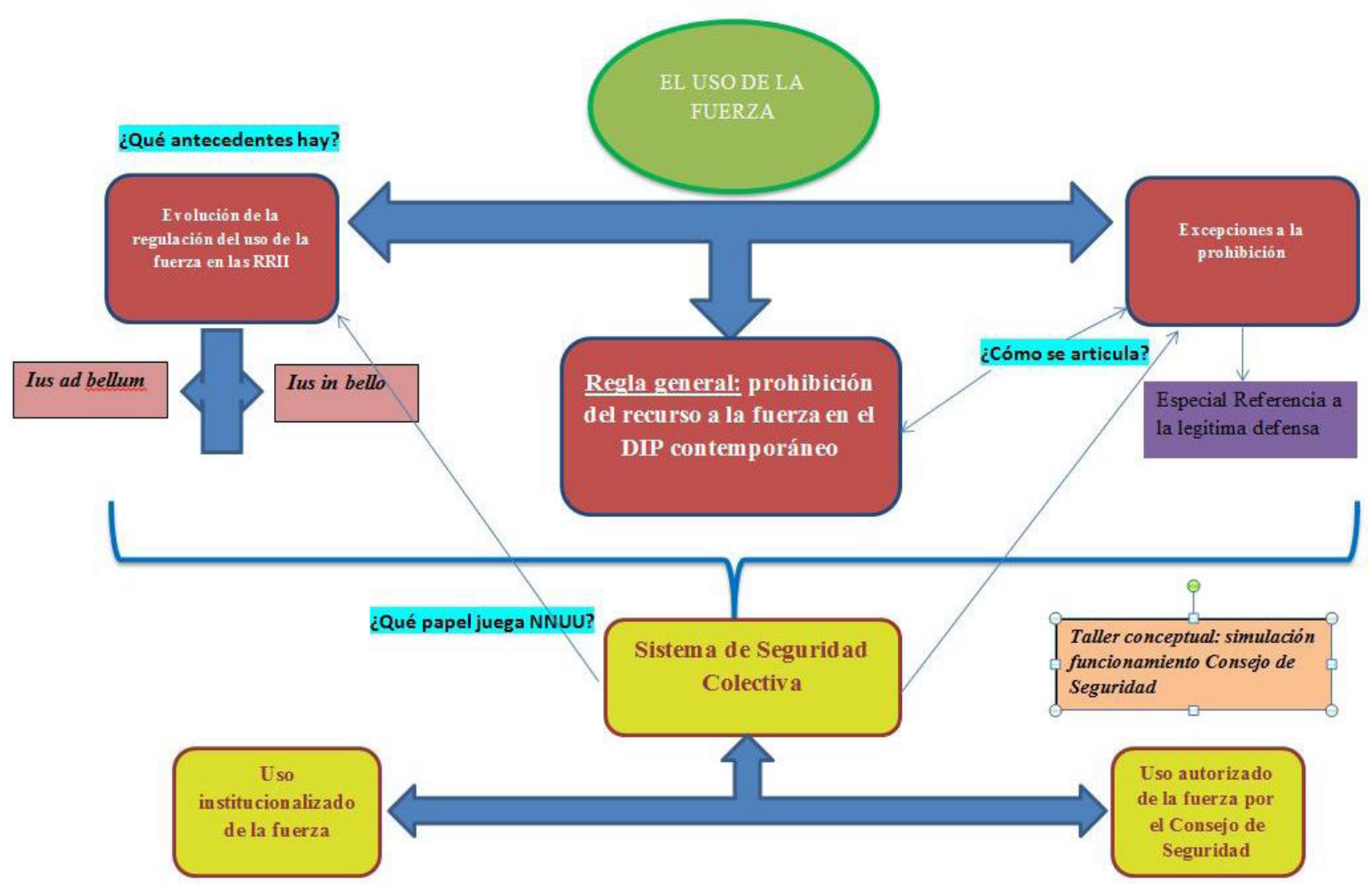

Figura 2. Mapa de contenidos de la lección 18

Jornadas de Formación e Innovación Docente del Profesorado | № 2 (2019) Esta obra se distribuye con la licencia Creative Commons

Reconocimiento-NoComercial-SinObraDerivada

Internacional (CC BY-NC-ND 4.0.) 


\section{Modelo Metodológico}

El modelo metodológico planteado para este sistema de docencia se resume en el esquema mostrado en la siguiente figura:

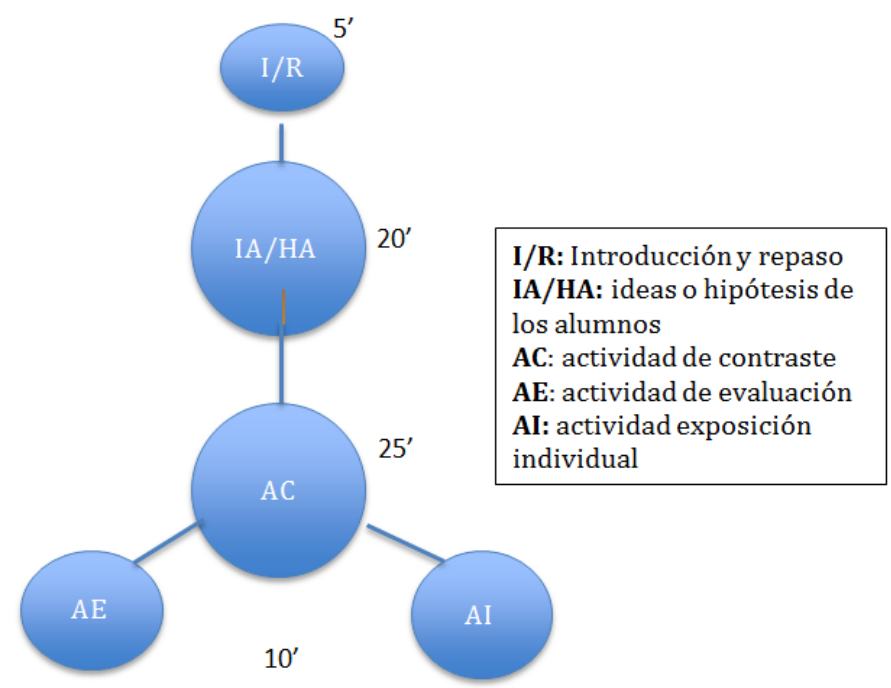

Figura 3. Modelo metodológico seguido en el Ciclo de Mejora Docente

De esta manera, durante el desarrollo de las clases se alternan actividades en las que los conceptos puramente teóricos son introducidos a través de la práctica, bien a través de un taller conceptual, como a través de debates de actualidad y visionado de medios audiovisuales. En cualquier caso, el profesor va guiando a los alumnos a través de explicaciones generales o preguntas abiertas para que sean los alumnos los que van construyendo el aprendizaje a través del diálogo interno (es decir, con ellos mismos argumentando sus posturas) y externo (exponiéndolas al resto de la clase). 


\section{Fichas de actividades}

Para cada actividad de este ciclo de mejora hemos realizado una ficha detallada sobre la fase metodológica a la que pertenece, el tiempo invertido en la actividad, un resumen del contenido de la misma y el material utilizado. Dado que son temas complejos y técnicos, sustituyo el cuestionario inicial de ideas por otra metodología: les facilito un resumen de la lección con los conceptos esenciales la semana anterior de empezar con la misma (generalmente los miércoles para empezar el lunes), de manera que el primer día se empieza con un cuestionario pero sobre la lección en sí y lo que han entendido de tras su lectura comprensiva.

Tabla 1. Secuencia de actividades del ciclo de mejora

\section{Primera sesión}

1

Fase metodológica: Introducción

$5-7$

Descripción: comienzo la sesión haciendo una breve introducción en la que explico el contenido general de la lección y lo que vamos a hacer en esta primera clase.

\begin{tabular}{|c|c|c|}
\hline $\mathbf{2}$ & Fase metodológica: Ideas/ hipótesis alumnos & $20^{-}$ \\
\hline $\begin{array}{l}\text { Descripción: Tras haber leído el resumen, hacen el cuestionario en clase. } \\
\text { Deben responderlo con las ideas y conceptos que han entendido del } \\
\text { resumen. }\end{array}$ \\
\hline
\end{tabular}

\begin{tabular}{|c|c|c|}
\hline 3 & Fase metodológica: Actividad de contraste & $20^{-}$ \\
\hline Descripción: Ponemos en común la corrección del cuestionario en voz alta. \\
\hline Recursos: ppt, pizarra. \\
\hline
\end{tabular}

\section{Segunda Sesión}

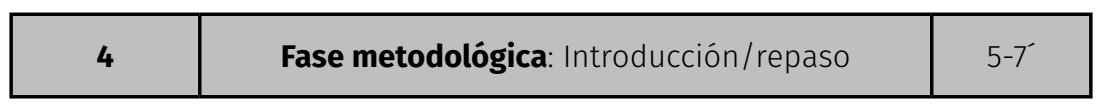

Jornadas de Formación e Innovación Docente del Profesorado | № 2 (2019) Esta obra se distribuye con la licencia Creative Commons Reconocimiento-NoComercial-SinObraDerivada Internacional (CC BY-NC-ND 4.0.) 
Descripción: comienzo la sesión haciendo un breve repaso de lo que vimos en la clase anterior para refrescar la memoria y les planteo lo que vamos a hacer en esa clase para que sean capaces de seguir el orden lógico de la misma.

Descripción: Comenzamos con la explicación de los puntos teóricos de la lección a través de preguntas generales que formulo sobre la base de la lectura del resumen lección que estamos viendo. Estas preguntas tienen que ver con los casos prácticos incluidos en el mapa conceptual y mi intención es que sean capaces de razonar ellos mismos sobre la problemática que presentan estos casos reales y establezcan las similitudes y diferencias entre ellos.

Recursos: pizarra, ppt., medios audiovisuales.

\section{Tercera sesión}

\begin{tabular}{|c|c|c|}
\hline 6 & Fase metodológica: Introducción/repaso & $5-7^{-}$ \\
\hline 7 & Fase metodológica: Actividad de contraste & $45^{-}$ \\
\hline \multicolumn{3}{|c|}{$\begin{array}{l}\text { Descripción: Continuo con la explicación de los puntos teóricos de la } \\
\text { lección con la misma dinámica que seguía en la clase anterior. Para ello } \\
\text { utilizo sobre todo medios audiovisuales como imágenes que suelen } \\
\text { facilitar que los alumnos relacionen los temas y los recuerden asimilando } \\
\text { los conceptos teóricos a la imagen. }\end{array}$} \\
\hline \multicolumn{3}{|c|}{ Recursos: pizarra, ppt., medios audiovisuales. } \\
\hline
\end{tabular}

\section{Cuarta sesión}

\begin{tabular}{|c|c|c|}
\hline $\mathbf{8}$ & Fase metodológica: Introducción/repaso & $5-7^{-}$ \\
\hline $\mathbf{9}$ & Fase metodológica: Ideas/ hipótesis alumnos & 45 \\
\hline $\begin{array}{l}\text { Descripción: Planteamos un caso práctico relativo a la temática de la } \\
\text { lección. Les dejo tiempo para que vayan trabajándolo en grupos pequeños } \\
\text { de entre } 3 \text { o } 4 \text { personas. Yo voy pasando grupo por grupo resolviendo } \\
\text { dudas y guiándoles. }\end{array}$ \\
\hline Recursos: internet, ordenadores, tablets. \\
\hline
\end{tabular}

Jornadas de Formación e Innovación Docente del Profesorado | № 2 (2019) Esta obra se distribuye con la licencia Creative Commons Reconocimiento-NoComercial-SinObraDerivada Internacional (CC BY-NC-ND 4.0.) 


\section{Quinta sesión}

\begin{tabular}{|c|c|c|}
\hline $\mathbf{1 0}$ & Fase metodológica: Introducción/repaso & $5-7^{-}$ \\
\hline $\mathbf{1 1}$ & Fase metodológica: Actividad de contraste & 45 \\
\hline $\begin{array}{l}\text { Descripción: Ponemos en común la corrección del caso práctico. De nuevo } \\
\text { yo solo les guío, pero corrigen ellos de manera que sea un debate abierto } \\
\text { e interactúen a la hora de argumentar sus respuestas. }\end{array}$ \\
\hline Recursos: ppt, pizarra.
\end{tabular}

\section{Sexta sesión}

\begin{tabular}{|c|c|c|}
\hline 13 & Fase metodológica: Introducción/repaso & $5-7^{-}$ \\
\hline 14 & Fase metodológica: evaluación - KAHOOT & $30-35^{\prime}$ \\
\hline \multicolumn{3}{|c|}{$\begin{array}{l}\text { Descripción: Los alumnos se autoevaluarán a través de un cuestionario } \\
\text { breve (unas } 10 \text { preguntas tipo test) sobre la lección para acabar y cerrar la } \\
\text { misma.Incluyo preguntas de las que vimos en el cuestionario inicial para } \\
\text { que ellos mismos vean su evolución desde el primer día que abordamos la } \\
\text { lección. }\end{array}$} \\
\hline \multicolumn{3}{|c|}{ Recursos: kahoot, proyector, móviles, internet. } \\
\hline 15 & $\begin{array}{l}\text { Fase metodológica: Actividad individual de } \\
\text { exposición }\end{array}$ & $5^{-}$ \\
\hline \multicolumn{3}{|c|}{$\begin{array}{l}\text { Descripción: Al alumno que le corresponde ese día realiza su exposición } \\
\text { breve de una noticia que hayan seleccionado previamente. }\end{array}$} \\
\hline \multicolumn{3}{|c|}{ Recursos: proyector, internet. } \\
\hline
\end{tabular}

\section{Séptima sesión}

\begin{tabular}{|c|c|c|}
\hline 16 & Fase metodológica: Introducción/repaso & $5-7^{-}$ \\
\hline $\mathbf{1 7}$ & Fase metodológica: Ideas/ hipótesis alumnos & $25^{\prime}$ \\
\hline $\begin{array}{l}\text { Descripción: De nuevo, tras haber leído el resumen de la lección, hacen el } \\
\text { cuestionario en clase. Deben responderlo con las ideas y conceptos que } \\
\text { han entendido del resumen. }\end{array}$ \\
\hline \multicolumn{2}{|l|}{ Recursos: internet, ordenadores, tablets. } \\
\hline
\end{tabular}

Jornadas de Formación e Innovación Docente del Profesorado | № 2 (2019) Esta obra se distribuye con la licencia Creative Commons Reconocimiento-NoComercial-SinObraDerivada Internacional (CC BY-NC-ND 4.0.) 
Descripción: Ponemos en común la corrección del cuestionario en voz alta.

Recursos: ppt, pizarra.

\section{Octava sesión}

\begin{tabular}{|c|c|c|}
\hline 19 & Fase metodológica: Introducción/repaso & $5-7^{-}$ \\
\hline $\mathbf{2 0}$ & Fase metodológica: Actividad de contraste & $45^{\circ}$ \\
\hline $\begin{array}{l}\text { Descripción: Comenzamos con la explicación de los puntos teóricos de la } \\
\text { lección a través de preguntas generales que formulo sobre la base de la } \\
\text { lectura del resumen lección que estamos viendo. }\end{array}$ \\
\hline \multicolumn{2}{|l}{ Recursos: pizarra, ppt., medios audiovisuales. } \\
\hline
\end{tabular}

\section{Novena sesión}

\begin{tabular}{|l|l|l|}
\hline $\mathbf{2 1}$ & Fase metodológica: Introducción/repaso & $5-7$ \\
\hline
\end{tabular}

22

Fase metodológica: Actividad de contraste

$45^{\prime}$

Descripción: Continuo con la explicación de los puntos teóricos de la lección con la misma dinámica que seguía en la clase anterior.

Recursos: pizarra, ppt., medios audiovisuales.

\section{Décima sesión}

\begin{tabular}{|c|c|c|}
\hline $\mathbf{2 3}$ & Fase metodológica: Introducción/repaso & $5-7$ \\
\hline $\mathbf{2 4}$ & Fase metodológica: Ideas/ hipótesis alumnos & 45 \\
\hline
\end{tabular}

Jornadas de Formación e Innovación Docente del Profesorado | № 2 (2019) Esta obra se distribuye con la licencia Creative Commons Reconocimiento-NoComercial-SinObraDerivada Internacional (CC BY-NC-ND 4.0.) 
Descripción: TALLER CONCEPTUAL. Para esta actividad los divido en grupos de 5-6 personas máximo y les explico que vamos a reproducir una simulación de cómo funciona el Consejo de Seguridad de Naciones Unidas. Cada uno de los grupos va a representar a un Estado miembro y les plantearé diversos casos en los que el Consejo debe pronunciarse: Guerra de Siria, Intervención en Libia, Ocupación Israelí en Palestina y situación de Venezuela. Para cada uno de los casos deben producir una declaración de la postura del Estado que representan conforme a Derecho Internacional. Voy por los grupos para resolver dudas y guiarles.

Recursos: internet, ordenadores, tablets.

\section{Decimoprimera sesión}

\begin{tabular}{|c|c|c|}
\hline $\mathbf{2 5}$ & Fase metodológica: Introducción/repaso & $5-7^{-}$ \\
\hline $\mathbf{2 6}$ & \multicolumn{1}{|c|}{ Fase metodológica: Actividad de contraste } & 45 \\
\hline $\begin{array}{l}\text { Descripción: Taller Conceptual. Ponemos en común las distintas posturas } \\
\text { de cada grupo. Para ello yo actúo como conductora de las discusiones } \\
\text { pero les dejo que interactúen y se rebatan las cuestiones que plantean. } \\
\text { Puntualmente incluyo asuntos que tengan relación y que puedan servir } \\
\text { para enriquecer el debate. }\end{array}$ \\
\hline Recursos: internet, ordenadores, tablets. \\
\hline
\end{tabular}

\section{Decimosegunda sesión}

\begin{tabular}{|c|c|c|}
\hline $\mathbf{2 7}$ & Fase metodológica: Introducción/repaso & $5-7^{-}$ \\
\hline $\mathbf{2 8}$ & \multicolumn{1}{|c|}{ Fase metodológica: evaluación - KAHOOT } & $30-35^{-}$ \\
\hline $\begin{array}{l}\text { Descripción: Los alumnos se autoevaluarán a través de un cuestionario } \\
\text { breve (unas 15 preguntas tipo test) sobre la lección para acabar y cerrar la } \\
\text { misma. Incluyo preguntas de las que vimos en el cuestionario inicial para } \\
\text { que ellos mismos vean su evolución desde el primer día que abordamos la } \\
\text { lección. }\end{array}$ \\
\hline \begin{tabular}{l} 
Recursos: kahoot, proyector, móviles, internet. \\
\hline
\end{tabular}
\end{tabular}

29

Fase metodológica: Actividad individual de exposición

Descripción: Al alumno que le corresponde ese día realiza su exposición breve de una noticia que hayan seleccionado previamente.

Recursos: proyector, internet. 


\section{Aplicación del CMD}

Cuaderno de sesiones

\section{Primera semana}

Tras la bienvenida y la introducción, comenzamos semana y lección nueva con el cuestionario tras su lectura individual del resumen. El cuestionario se compone de unas 4 preguntas breves sobre las cuestiones más básicas de la lección.

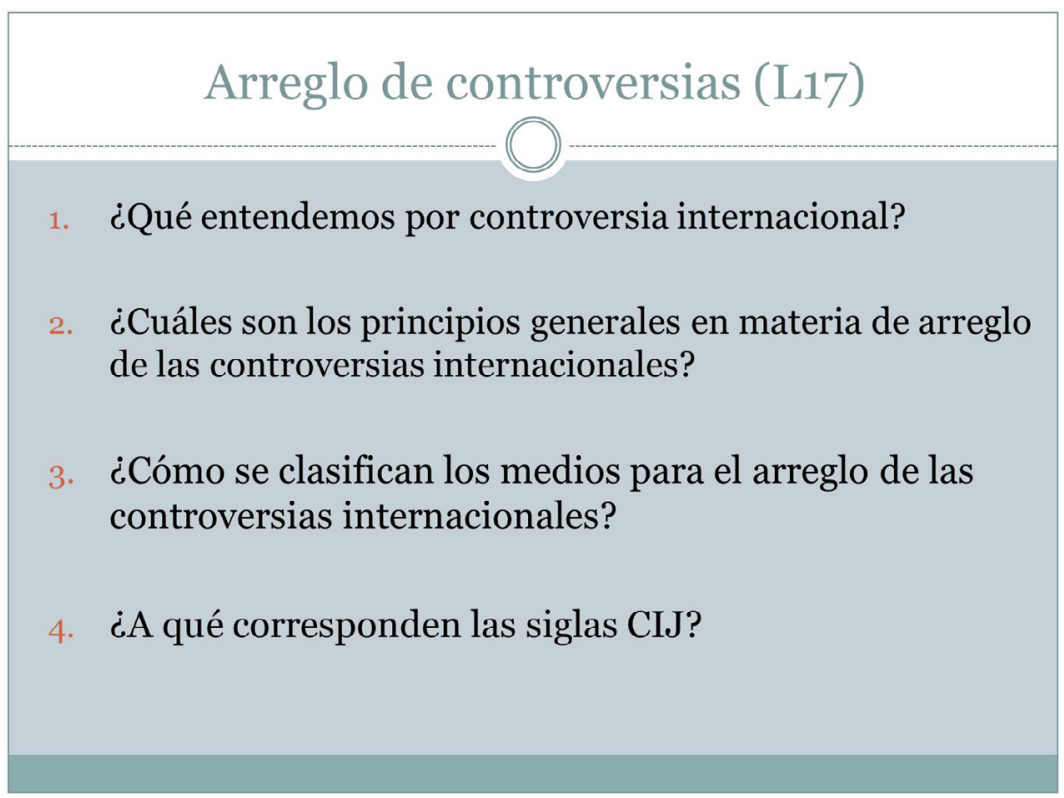

Figura 4. Cuestionario previo Lección 17

Pasados unos veinte minutos todos han terminado, así que lo ponemos en común. Ellos van respondiendo en voz alta y más que una corrección se trata de un ejercicio colectivo de comprensión en el que yo les voy guiando e intentando que vean los fundamentos jurídicos razonados

Jornadas de Formación e Innovación Docente del Profesorado | № 2 (2019) Esta obra se distribuye con la licencia Creative Commons Reconocimiento-NoComercial-SinObraDerivada 
sobre las cuestiones esenciales del tema. No solo acabo la clase con buena sensación porque veo que van entendiendo conceptos sino que ellos mismos me lo confirman: espontáneamente varios alumnos dicen en voz alta que "este sistema" les "gusta". Corroboro que efectivamente muchas nociones han calado entre ellos a través de las dos siguientes sesiones en las que voy explicando la lección. Utilizo siempre que puedo imágenes y vídeos porque creo que les ayuda a recordar mejor las ideas y en algunos casos nos ofrecen la oportunidad de debatir sobre los temas si plantea cuestiones controvertidas. Asimismo, uso muchos ejemplos reales de controversias internacionales entre Estados y lo cuento casi como una historia observando que esto les despierta el interés y la curiosidad.

\section{Segunda semana}

Comenzamos la semana con el trabajo en grupos de un caso práctico sobre la materia de la lección. Mientras van trabajando voy pasando por los grupos para resolver dudas y comprobar cómo se aproximan al caso. Prefiero que se trabajen los casos prácticos en clase porque cuando tienen que trabajarlos en casa muchas veces lo copian de alguien que los tenga hecho pero no ponen el mismo interés en resolverlo. En clase, sin embargo, aprovechan la hora y se ven forzados a trabajar por el grupo y en su propio beneficio. Acaban y corregimos el caso práctico en la siguiente sesión. El resultado es bueno y eso me confirma que la mayoría ha sido capaz de comprender los fundamentos de la lección y de aplicarlos a la práctica, a la vida real. A continuación, pasamos a las exposiciones individuales, donde de nuevo utilizo los temas para repasar conceptos ya vistos no solo de esta lección sino también de las anteriores. Tras cada intervención les planteo cuestiones de actualidad e intento reconducirlas a los puntos fundamentales de la parte teórica de la lección, con lo que pueden ir conectando ideas y viendo la aplicación práctica de los contendidos teóricos. Acabamos las sesiones de esta segunda semana con un kahoot en el que las 
preguntas son muy similares a las del cuestionario inicial, precisamente para comprobar si ha habido evolución entre el primero y este último. En algunas preguntas, la clase por unanimidad resuelve con la pregunta correcta.

\section{Tercera semana}

De nuevo comienzo introduciendo la lección que vamos a tratar en las siguientes sesiones. Le dedico siempre unos minutos a esta tarea porque quiero que los alumnos sean capaces de entender el orden lógico de los temas que se estudian y sobretodo su relación con el resto de lecciones de manera conjunta, como un todo de la misma asignatura. Así, pretendo que no automaticen las lecciones sino que entiendan los ejes de conexión entre unas y otras y desarrollen su pensamiento relacional. A continuación, pasamos a realizar el cuestionario del resumen de la lección 18 que han debido leer previamente. De nuevo el cuestionario consta de cuatro preguntas que versan sobre cuestiones esenciales de la lección.

\section{El control del uso de la fuerza}

1. ¿Dónde aparece regulado el ppio de prohibición general del uso de la fuerza? ¿Dónde se ha desarrollado posteriormente dicho ppio?

2. ¿Bajo qué circunstancias cabe acudir al recurso de la legítima defensa en DIP. ¿Cuáles son los límites que deben cumplirse para poder hacer uso de este recurso?

3. Describa brevemente en qué consiste el sistema de seguridad colectiva de NNUU.

4. ¿Cuáles son las características principales de las OMPs?

Figura 5. Cuestionario previo Lección 18

Jornadas de Formación e Innovación Docente del Profesorado I № 2 (2019) Esta obra se distribuye con la licencia Creative Commons Reconocimiento-NoComercial-SinObraDerivada Internacional (CC BY-NC-ND 4.0.) 
Una vez más los resultados del cuestionario son muy buenos, aclaran ideas previas y van interiorizando los principales conceptos. La explicación de las sesiones posteriores se desarrolla igualmente de manera muy satisfactoria. El grupo estaba muy involucrado y con muchas de las imágenes surgieron debates muy interesantes en el que prácticamente todos participaban y que opino que contribuyen mucho a su aprendizaje.

\section{Cuarta semana}

El protagonismo de esta cuarta semana lo recibe sin duda la actividad del taller conceptual. Aunque al principio parecen no entender del todo en qué consiste el ejercicio, la idea de trabajar en grupo y en un tono más informal a lo habitual parece entusiasmarles. Decido además proponerles un aliciente extra: 0,25 en la nota final al grupo que realice mejor la actividad, lo que supone para todos un buen impulso motivacional. Al igual que en otras ocasiones en las que he puesto en práctica el taller conceptual, la dinámica me resulta muy positiva: trabajan bien y yo puedo dedicarme unos 5-7 minutos a supervisar cada grupo y a resolver dudas. En la puesta en común de los resultados compruebo gratamente que todos los grupos han seguido una línea similar y acertada a la hora de resolver el caso, lo que me hace reafirmarme en la idoneidad de este tipo de actividades pero también en la necesidad de que se propongan de manera concreta y estudiada previamente para que los resultados sean satisfactorios. El único inconveniente que observo es que es una tarea que necesita tiempo y eso nos obliga a robarle un buen rato a la clase del miércoles y por tanto a realizar el kahoot con cierta urgencia, al igual que las intervenciones individuales. Para futuras sesiones debo controlar mejor el tiempo, aunque me sigue pareciendo dificil cuando el debate o las intervenciones individuales son tan interesantes.

Jornadas de Formación e Innovación Docente del Profesorado | № 2 (2019) Esta obra se distribuye con la licencia Creative Commons Reconocimiento-NoComercial-SinObraDerivada 


\section{Evaluación del aprendizaje de los estudiantes}

\section{Escaleras de aprendizaje}

Para evaluar el aprendizaje efectivo de los alumnos, tomé como punto de partida el cuestionario inicial de cada lección y el kahoot final en el que además la aplicación me da los datos en porcentajes. A pesar de que los cuestionarios iniciales deben hacerlos tras la lectura de los resúmenes, en muchos casos leen sin entender por lo que fallan en muchas preguntas. En el kahoot final las preguntas no son exactamente las mismas sino que las replanteo a través de ejemplos prácticos de los que hemos visto en clase y el resultado es muy bueno. El seguimiento de las explicaciones ha sido mayoritario y compruebo que ilustrando cada cuestión con casos prácticos (o incluso estableciendo relaciones entre la materia y la serie del momento, Juego de Tronos) retienen mejor las ideas y las hacen propias. Tanto en el cuestionario inicial como en el final, establezco 3 niveles de aprendizaje que reflejan las dificultades que pueden encontrar los alumnos. En todos los casos, el "salto" mayor se encuentra entre el primer y el segundo escalón. Los resultados globales obtenidos entre ambos cuestionarios de las dos lecciones pueden verse en la siguiente Figura.

Jornadas de Formación e Innovación Docente del Profesorado | № 2 (2019) Esta obra se distribuye con la licencia Creative Commons Reconocimiento-NoComercial-SinObraDerivada 

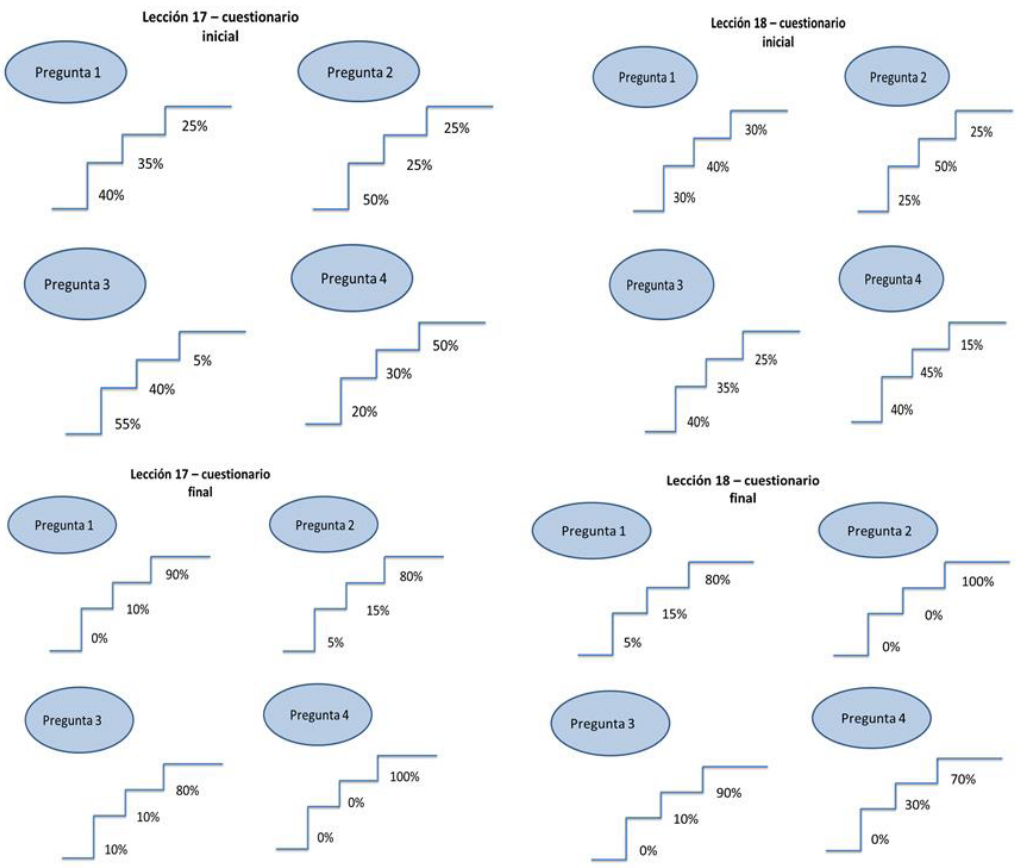

Figura 6: Escaleras de aprendizaje

\section{Evaluación del CMD}

Mi objetivo principal es poder extender el próximo ciclo de mejora a un cuatrimestre entero de la asignatura. Para ello, mantendré el formato de los mapa de contenidos, los cuales resultan indispensables para generar una idea previa de cuáles son las cuestiones fundamentales en las que debo insistir y cómo plantear la línea de aprendizaje.

La metodología resulta ser muy efectiva, por lo que pretendo mantenerla no solo en los ciclos de mejora sino en toda mi docencia. Asimismo, quisiera plantear a través de la metodología y de los mapas de contenidos, ejercicios que faciliten el pensamiento relacional de los alumnos. Observo las dificultades que encuentran para establecer las relaciones materiales y formales entre conceptos, 
ideas y temas de una misma asignatura, así como entre materias dentro de la misma titulación, por más cercanas que estas sean. Por ello, quisiera potenciar estos aspectos en los próximos ciclos de mejora docente que desarrolle dentro de la REFID.

Un aspecto que necesito repensar y desarrollar es el sistema de evaluación, ya que me gustaría que esta nueva aproximación a la asignatura les proporcionase, además de resultados de aprendizaje, calificaciones acordes a dichos resultados. Quizás un sistema en el que la evaluación continua cobre más protagonismo sea la solución, aunque se me antoja complicado si los grupos son tan numerosos pues dificulta la tarea del seguimiento semanal del alumnado.

Con respecto a los principios didácticos que han inspirado la experiencia docente, destacaría dos en concreto: el estudiante como constructor del conocimiento y el aprendizaje funcional. El primero de ellos es la base de todo el planteamiento del ciclo de mejora: partiendo de la premisa de que los conocimientos previos condicionan la manera en la que el alumno enfoca y desarrolla el aprendizaje, las actividades que se proponen favorecen que el mismo se de en un ambiente de interacción social (con casos reales, con otros compañeros, a través de material audiovisual etc) y el docente facilita y conduce el proceso en sí. Por otro lado, la propia experiencia personal me demuestra que todo aquello que se aprende pura y únicamente de memoria se olvida, no prevalece en nuestra mente, es por ello que procuro que el aprendizaje sea de carácter funcional y aplicado a la realidad, de manera que los alumnos constaten que lo que vemos en clase no es algo que deban memorizar sin sentido sino que les va a servir para su vida real. Esta idea se manifiesta especialmente en la actividad del comentario de noticias de actualidad. 


\section{Conclusiones}

Este artículo refleja las principales cuestiones relativas al diseño, la aplicación y la evaluación de un ciclo de mejora docente de la asignatura Derecho Internacional Público del segundo curso del Grado en Derecho de la Universidad de Sevilla. La aproximación que se plantea para el propuesto ciclo de mejora docente implica una ligera transformación del papel del docente, de manera que la clásica lección magistral se limita y se readapta para mejorar los resultados del aprendizaje, siendo los estudiantes los que generan conocimiento a través de las actividades que el docente previamente plantea y les propone.

De este modo, el modelo metodológico y las tareas diseñadas han proporcionado unos resultados muy satisfactorios y así se ha visto reflejado también en la evaluación y la calificación final del grupo, lo que contribuye a que me reafirme en la convicción de que este es el camino a seguir en el futuro para mi docencia universitaria. 


\section{Referencias bibliográficas}

Don Finkel, Dar clase con la boca cerrada, Publicaciones Universidad de Valencia, 2008.

Ken Bain, Lo que hacen los mejores profesores universitarios, Publicaciones Universidad de Valencia, 2007.

Rafael Porlán (Coord.), Enseñanza Universitaria. Cómo mejorarla, Ediciones Morata, 2017.

Carlos Jiménez Piernas, Introducción al Derecho Internacional Público: práctica española adaptada al EESS, Ed. Tecnos, 2a ed., Madrid, 2011.

José Antonio Pastor Ridruejo, Curso de Derecho Internacional público y Organizaciones Internacionales, 22a ed., Tecnos, Madrid, 2018

Juan Antonio Carrillo Salcedo, Curso de Derecho Internacional Público. Introducción a su estructura, dinámica y funciones, Tecnos, Madrid, 1991, (reimp. 1996)

Ana Gemma Lopez Martín y José Antonio Perea Unceta (dir.), El cine y el derecho internacional. Materiales de prácticas para la docencia, Bogotá, Universidad El Bosque, 2014.

Jornadas de Formación e Innovación Docente del Profesorado | № 2 (2019) Esta obra se distribuye con la licencia Creative Commons Reconocimiento-NoComercial-SinObraDerivada 